\title{
Movimento divisionista e as diversas interpretações na historiografia: análise do Movimento Guaicuru
}

\author{
Thaís Leão Vieira* \\ Aline Xavier Cana Verde**
}

Este artigo pretende discutir as múltiplas interpretações produzidas sobre o Movimento Cultural Guaicuru. Trabalhamos com a possibilidade de que os índios Guaicurus foram importantes para a construção de determinada identidade sul-mato-grossense considerando, a partir do Movimento Guaicuru, que a nação Guaicuru foi a primeira plataforma social, econômica, política e cultural em abrangência territorial correspondente ao novo Estado. Ressaltamos assim, o surgimento do Movimento Cultural Guaicuru associado a essa busca de uma identidade sulmato-grossense.

Palavras-Chave: Movimento Divisionista, Guaicuru, Identidade Cultural.

This article discusses the multiple interpretations produced on the Guaicuru Cultural Movement. We work with the possibility that Guaicurus Indians were important for the construction of a certain identity of Mato Grosso do Sul, considering that, from this movement, Guaicuru
Ele (movimento guaicuru) foi o primeiro momento de busca de uma identidade e que perdura até hoje, [...] porque o Guaicuru é o único que foi nação, era nação Guaicuru, então nós, fomos a nação Guaicuru, daí a importância dessa busca dessa identidade, e eles como nação aglutinavam outras tribos, eles eram uma síntese, além da beleza estética...

Idara Duncan

Ð sse artigo consiste em analisar $\sqsubset$ a discussão sobre as diversas interpretações do Movimento Divisionista na historiografia, o surgimento do Movimento Cultural Guaicuru e a busca de uma determinada identidade sul-matogrossense.

\footnotetext{
* Professora do curso de História da UFMS, mestre e doutoranda em História pela UFU. thais_leao@yahoo.com.br

** Graduada em História pela UFMS - Campus de Coxim, MS. alinexaviercanaverde@ gmail.com
} 
nation was the first social, economic, political and cultural platform in territorial scope corresponding to the new State. We emphasize therefore the emergence of the Guaicuru Cultu- ral Movement associated with the search for a Mato Grosso do Sul identity.

Keywords: Secessionist movement, Guaicuru, Cultural Identity

Após o movimento divisionista, em 1979, há um questionamento acerca da busca e da construção identitária de Mato Grosso do Sul por setores produtivos de arte cultura deste Estado, pois esses setores se depararam com a necessidade de identificar valores culturais da região correspondente com o novo Estado. Do ponto de vista artístico e cultural, essa construção deu-se pelo Movimento Cultual Guaicuru que tinha como membro fundador o historiador e artista plástico Henrique de Melo Spengler que usou os ícones e as cores da arte Guaicuru como elementos constituintes de suas obras.

Os índios Guaicurus foram importantes para a construção da identidade sulmato-grossense considerando que a nação Guaicuru foi a primeira plataforma social, econômica, política e cultural em abrangência territorial correspondente ao novo Estado. Outra questão que foi analisada foi a influência dos índios Guaicurus na construção identitária de Mato Grosso do Sul tendo eles como representativo de um povo guerreiro, lutador, resistente e símbolo de grande determinação ${ }^{1}$.

A ocupação da região de Mato Grosso do Sul remonta ao século XVI, quando a região, habitada por dezenas de tribos indígenas, viu seu território ser invadido por estrangeiros de diferentes nacionalidades que aqui buscavam riqueza fácil. Com a chegada da primeira expedição de exploradores espanhóis vindos em 1527 pelos rios Paraguai e Cuiabá em busca principalmente do ouro - pois acreditavam chegar às minas de ouro do Peru - estes vão conquistando terras, introduzem gado na região e começam a exploração de erva-mate. A miscigenação entre índios e espanhóis resulta nos paraguaios e, nos séculos XVII e XVIII, índios e paraguaios permanecem no sul de Mato Grosso como donos da terra.

\footnotetext{
${ }^{1}$ Vera Alice Cardoso ressalta que "A região deve ser concebida como um território contínuo. Dentre deste, ocorrem os processos de produção (de bens e serviços) e de reprodução de um modelo determinado de convivência social. Assim, a região pode coincidir ou não com fronteiras politicamente estabelecidas, como são as fronteiras estados nacionais ou as fronteiras entre os estados membros de uma federação." Cf.: SILVA, Vera Alice Cardoso. Regionalismo: O enfoque metodológico e a concepção histórica. SILVA, Marcos (coord.). República em Migalhas. Historia Regional e Local. São Paulo: Marco Zero/ CNPq, 1990, p. 45.
} 
A descoberta do ouro em Cuiabá no início do século XVIII propicia a expansão portuguesa em Mato Grosso, pois são atraídos pela cobiça do ouro e pela facilidade do braço escravo. Os portugueses acabaram com as reservas do precioso metal em Cuiabá, com as quais ampliaram a riqueza da coroa portuguesa ${ }^{2}$. O sul de Mato Grosso, pela ausência de minérios, tem na exploração de gado pelos índios, paraguaios e portugueses, a sua subsistência. A expansão dessa atividade favorece o aparecimento de arraiais e cidades, entre elas Campo Grande. Vieram gaúchos fugindo das revoluções rio-grandenses, que ocuparam a "faixa da fronteira", os mineiros chegaram até Campo Grande, os paulistas também avançavam para o interior, além dos paraguaios, bolivianos, argentinos, uruguaios e excombatentes que foram ficando por essas terras.

As transformações econômicas que o Brasil estava passando na segunda metade do século XIX, resultantes do surgimento da indústria e do desenvolvimento dos meios de transporte, fizeram acelerar a ocupação territorial de algumas regiões. A chegada da Estrada de Ferro Noroeste do Brasil (NOB) em Campo Grande promoveu a integração econômica pelo interior do estado e com o país. Ao lado de diferentes raízes históricas e culturais, advindas da origem de suas populações, a grande desigualdade geográfica existente entre as porções norte e sul do antigo Estado fez com que a ocupação econômica do seu território fosse de forma diversa.

As próprias raízes históricas das regiões sul e norte diferenciam-nas. A região Sul, com extraordinária potencialidade agrícola, de colonização relativamente recente, tendo como principais pólos Campo Grande, Dourados, Corumbá e Ponta Porã, liga-se aos grandes centros de produção da região Sudeste e ao Paraná e aos corredores de exportação de Santos e Paranaguá. A região Norte apresenta características pré-amazônicas e reúne grandes possibilidades nas atividades agropecuárias, florestais e de mineração. ${ }^{3}$

\footnotetext{
${ }^{2}$ A descoberta das lavras em Cuiabá fez com que tivessem amplas possibilidades para o comércio descoberto com abastecimento das áreas mineratórias que traziam consigo, principalmente a partir da terceira década do século XVIII, um grande afluxo de comerciantes portugueses que após se estabelecerem enriqueceram. Cf.: AMORIM, Marcos Lourenço. "O segundo Eldorado"brasileiro, Navegação Fluvial e Sociedade do território do ouro. De Araritaguaba à Cuiabá (1719-1838). Dissertação (Mestrado em Historia) Universidade Federal de Mato Grosso do Sul, Dourados, 2004. ${ }^{3}$ GRESSIER, Lori Alice; SWWENSSON, Laura Joppert. Aspectos Históricos do Povoamento e da colonização de Mato Grosso do Sul: destaque especial ao município de Dourados. Dourados: s/ editora, 1998, p. 36.
} 
Enquanto a porção norte possui características pré-amazônicas, beneficiando-se de incentivos específicos para o seu desenvolvimento, a porção sul, objeto da colonização relativamente recente, concentrou a maior parte da população e das atividades produtivas. A criação do Estado de Mato Grosso do Sul possui uma série de interpretações sendo resultado de um longo movimento, com características socioeconômicas, políticas e culturais que permeou sua formação histórica recente. De acordo com Alisolete Weingartner o movimento divisionista no sul de Mato Grosso tem sua origem no fim do século XIX, quando alguns políticos corumbaenses divulgam um manifesto ${ }^{4}$, no qual propunham a transferência da capital de Mato Grosso para Corumbá. A atitude desses políticos não se tornou vitoriosa, mas mostrou que essa tímida ação política permitiu marcar o início de uma longa história de lutas e revezes.

Alguns fatores como o desenvolvimento da pecuária, o crescimento socioeconômico das vilas e cidades, a exploração da erva-mate pela companhia Matte Laranjeira e a ligação ferroviária entre o sul de Mato Grosso e São Paulo, marcaram a origem do movimento divisionista. Os anos de 1889 e 1930 são marcados pela formação das oligarquias sul-mato-grosssenses que lutam pelo reconhecimento de posse de terra. São nessas lutas que se manifestou a idéia divisionista.

O sul de Mato Grosso por alguns séculos foi reduzido à condição de reserva de gado cujos portos fluviais no rio Paraguai, asseguravam a Cuiabá o acesso aos grandes centros econômicos e políticos. Porém, após a guerra com o Paraguai ${ }^{5}$, as vilas e cidades cresciam alheios as ordens e a assistência político-administrativas de Cuiabá. O sul de Mato Grosso, no entanto desponta como uma economia disponível que substitui a economia mineradora do norte de Mato Grosso. Entretanto, Cuiabá mantém-se com centro político-administrativo estadual. Com a ca-

\footnotetext{
${ }^{4}$ As divergências entre o norte e sul de Mato Grosso, são anteriores à proclamação da república. Nos dias 6 e 12 de junho de 1889, o jornal A Gazeta publica um manifesto de políticos corumbaenses, no qual reclamam a falta de assistência política administrativa. Os políticos já nesse manifesto, propõem a transferência da capital para Cuiabá para Corumbá. Cf. WEINGARTNER, Alisolte Antônio dos Santos. Movimento Divisonista no Mato Grosso do Sul. Porto Alegre: Edições EST, 2002, p. 02.

${ }^{5}$ Foi a guerra estabelecida em $1^{\circ}$ de maio de 1865 quando Brasil, Uruguai e Argentina assinaram o Tratado da Tríplice Aliança, que tinha como objeto legitimar a Guerra do Paraguai e, assim submetêlo ao sistema político-econômico dominante no Prata. Cf. SQUINELO, Ana Paula. A Guerra do Paraguai, essa desconhecida... Ensino, memória e história de um conflito secular. Campo GrandeMS: UCDB, 2002.
} 
pital em Cuiabá o governo enfrenta alguns problemas pra administrar o extenso território mato-grossense, como as grandes distâncias entre a capital e as cidades do sul, falta de comunicação eficiente, não apenas com as cidades mato-grossenses, mas também com a sede do governo federal no Rio de Janeiro. Esses problemas fazem de Cuiabá uma capital isolada, dentro do próprio Estado.

O desenvolvimento econômico do sul de Mato Grosso fez com que houvesse um fortalecimento político de um grupo formado de grandes proprietários rurais da região que praticam a pecuária, atividade econômica que no estado foi desenvolvida a partir de grandes extensões de terra. Este grupo fundamenta seu poder no latifúndio e na associação a outros fazendeiros e não proprietários, essas relações fortalecem politicamente, alguns grupos de famílias, dando origem à formação das oligarquias sulinas desvinculadas das já existentes no norte. A chefia das oligarquias, tanto no norte quanto no sul, é exercida pelos "coronéis"'. Inicialmente o movimento divisionista não tem um programa político definido, os objetivos divisionistas quase sempre se confundiam com os interesses pessoais dos coronéis. Percebe-se que nesse período, que era a elite formada pelos fazendeiros que defendiam a idéia divisionista.

Assim, de um lado, as oligarquias do Norte que detêm o poder político-administrativo estadual e usam dessa autoridade para submeter e "situar a região Sul como um simples suporte ou elemento de barganha" na composição política estadual. De outro lado, o Sul de Mato Grosso, embora distante do centro da decisão estadual, resiste e se opõe ao controle nortista exercido pelos coronéis a serviço da Matte Laranjeira e governo estadual. $^{7}$

Outros fatores também contribuíram para reforçar a divulgar a idéia divisionista. A constante chegada de migrantes, o reconhecimento e a legalização das posses de terras aos privilégios da Companhia Matte Laranjeira criam dificuldades sócio-econômicas e políticas. Com isso, alguns se aliam às oligarquias sulinas já existentes, outros formam novas oligarquias. E essa situação favorece a expan-

\footnotetext{
${ }^{6} \mathrm{O}$ coronelismo, na primeira República, é uma forma peculiar de manifestação do poder privado que coexiste com um regime político de extensa base representativa. Esse coronelismo é alimentado pelo poder público, que não prescindia de um eleitorado rural, sob o domínio dos proprietários de terra. Cf.: WEINGARTNER, Alisolete Antônio dos Santos. Movimento divisionista no Mato Grosso do Sul. Porto Alegre: Edições EST. 2002.
}

${ }^{7}$ Ibidem, p. 26. 
são do divisionismo, e as divergências entre norte e o sul do estado crescem havendo um distanciamento sócio-econômico e político entre essas sociedades. A partir de 1920, com a transferência do comando da Circunscrição Militar para Campo Grande, e o aumento do contingente militar no sul de Mato Grosso, as oligarquias sulinas decepcionadas com as antigas alianças aliam-se aos militares e adotam sugestões de outros movimentos vindos de fora do estado como forma de fortalecer a causa local.

\begin{abstract}
As causas dessa transferência não estão bem esclarecidas, seja pela instabilidade que caracteriza o Sul ou por causa da importância econômica que Campo Grande passa a desfrutar. O que importa, no momento, é a influência que os militares passaram a exercer nos confrontos armados no Sul de Mato Grosso e no movimento divisionista. Isso porque essa Circunscrição congrega os destacamentos militares em todo Mato Grosso, particularmente nas fronteiras do Sul do Estado. ${ }^{8}$
\end{abstract}

Com isso, os coronéis deixavam a liderança para permanecerem subordinados aos chefes militares. Essa subalternidade aos chefes militares e o alheamento do norte contribuem para que os coronéis sulinos ficassem cada vez mais independentes das oligarquias nortistas. A esse fator é somada a regularização das viagens ferroviárias que propiciaram a chegada de novos imigrantes e a dinamização da economia sul-mato-grossense. Outra conseqüência das viagens ferroviárias é a vinculação do sul de Mato Grosso com a economia paulista e o conseqüente desenvolvimento das cidades exportadoras de gado, particularmente Campo Grande, e a transferência do eixo econômico Cuiabá - Corumbá - Rio Paraguai para Campo Grande. Esta transferência possibilita a formação de novas lideranças políticas ligadas ao comércio e a outras atividades profissionais, e um crescimento demográfico na região sul-mato-grossense.

Essa interferência na organização das cidades pela Companhia da Estrada de Ferro Noroeste do Brasil e a regularização das viagens ferroviárias dinamizaram a economia sul-mato-grossense, transformando o Sul de Mato Grosso em principal zona arrecadadora do Estado. ${ }^{9}$

Esse quadro, de novos fatores de ordem sócio-econômica e política, trazem significativas mudanças no movimento divisionista, o qual extrapola ervais e atin-

\footnotetext{
${ }^{8}$ Ibidem, p.62

${ }^{9}$ Ibidem, p. 36.
} 
gem as cidades exportadoras de gado, particularmente Campo Grande. É o início da urbanização do movimento. De 1930 a 1945 é o período em que o movimento começa a organizar-se e desenvolver pressões políticas junto ao governo federal. Em 1932 os sul-mato-grossenses aliam-se aos paulistas e lutam na revolução constitucionalista e, após três meses de luta, os divisionistas e constitucionalistas são derrotados. Esse momento serviu para divulgar a idéia divisionista e Campo Grande torna-se o centro político da difusão do movimento.

Dois anos depois, o Congresso Nacional reunia-se para elaborar uma nova constituição. Jovens e estudantes fundam a liga sul-mato-grossense que, inicialmente, tinha por objetivo angariar apoio da sociedade sul-mato-grossense para um manifesto que seria encaminhado ao Presidente do Congresso Nacional Constituinte e dos políticos tanto da esfera estadual quanto na federal. A liga desencadeia a campanha divisionista no sul de Mato Grosso, coletando treze mil assinaturas, com as quais visava sensibilizar o governo federal, particularmente os constituintes, para que eles na elaboração da Constituição aprovassem a divisão do Estado de Mato Grosso ${ }^{10}$.

Após a promulgação da constituição, os divisionistas são derrotados e Getúlio Vargas adota a política nacionalista "Marcha para o Oeste" entre outros objetivos, a segurança das fronteiras. Para isso mandou instalar novas unidades militares no sul de Mato Grosso. $\mathrm{O}$ aumento do contingente militar efetivou outros objetivos do governo que era a manutenção da "ordem e progresso" dessa região de fronteira. Os divisionistas são envolvidos pela política Vargas; a companhia Matte Laranjeira adapta-se a essa política e altera sua estratégia em relação a unidade estadual, ou seja, os ervais estavam devastados e também a

\footnotetext{
${ }^{10}$ A Liga Sul-Mato-Grossense organizou por meio de manifestos, publicação de panfletos, artigos em jornais e um abaixo-assinado contendo milhares de assinaturas dos moradores da parte Sul do Estado de Mato Grosso, entregue para os Constituintes. De novembro de 1933 a julho de 1934 (as eleições são realizadas dia 3 de maio de 1933 e a Assembléia Constituinte é instalada em 15 de novembro de 1933), o país viveu sob a égide da Assembléia Nacional Constituinte encarregada de elaborar a nova Constituição Brasileira que iria substituir a Constituição de 1891. Foram meses de intensa articulação e disputa política entre o governo e os grupos que compunham a Constituinte. Após oito meses de discussões, no dia 16 de julho de 1934, foi promulgada a nova Constituição e no dia seguinte Getúlio Vargas se reafirmou como presidente. Cf.: BITTAR, Marisa. Mato Grosso do Sul: do Estado sonhado ao Estado construído (1892-1997). , São Paulo, 1997. 2 v. Tese (Doutorado em História) - FFLCH/USP.
}

${ }^{11}$ Cf.: WEINGARTNER, Alisolete Antônio dos Santos. Op. Cit. 
política do Instituto Brasileiro do Matte, criado por Getúlio Vargas, não lhe favoreciam grandes lucros. Por isso ela permite que o governo estadual regularize as posses de terras dos moradores dos ervais, em troca de indenizações sobre os arrendamentos.

De acordo com Weingartner em 1943 Getúlio Vargas em nome da segurança das fronteiras, cria o território de Ponta Porã, o qual deixa de fora da nova unidade Campo Grande, a principal cidade divisionista. A criação do território de Ponta Porã não atendeu aos interesses divisionistas, não satisfez a política da Companhia Matte Laranjeira e também não agradou ao governo estadual.

Nesse período, o sul de Mato Grosso é marcado por grandes prosperidades, a qual não era suficiente para equilibrar as finanças estaduais. Percebe-se, nessa fase, que a política de Getúlio Vargas foi um dos obstáculos aos objetivos divisionistas. Percebe-se ainda, a formação de novas oligarquias e a Companhia Matte Laranjeira, gradativamente, retira-se dos ervais.

Após a deposição de Getúlio Vargas, o novo presidente da República é o general Eurico Gaspar Dutra, que era mato-grossense de Cuiabá. Ele adota uma política de redemocratização do país, a qual reforça como política interna a integração nacional que incentiva a manutenção da unidade estadual. Após a promulgação da constituição, o governo federal extingue o território de Ponta Porã reintegrando a região ao Estado de Mato Grosso. Apesar dessa política, os divisionistas, durante as reuniões da assembléia constituinte, reorganizam-se e tentam a transferência da capital de Cuiabá para Campo Grande.

As iniciativas divisionistas desse período são frustradas, em parte, devido a grande representatividade política dos sul-mato-grossenses nas esferas estadual e federal, e também, por causa da política de integração nacional do governo federal. Percebe-se que nesse período depois de várias reformulações em sua estrutura organizacional, a Companhia Matte Laranjeira mostra desinteresse em reflorestar os ervais.

O golpe de 31 de março de 1964 põe fim a um período de democracia e inicia um regime militar autoritário. Os militares buscando um maior controle dos problemas da sociedade adotam a política do desenvolvimento e de segurança nacional, o que permitiu a criação de programas que facilitaram o desenvolvimento de alguns Estados, entre eles Mato Grosso. Neste período, os políticos divisionistas 
aproximam-se dos militares, o que lhes permite tomar parte de algumas comissões que estudam (secretamente) as potencialidades políticas que impediam a divisão do Estado de Mato Grosso.

Após vários estudos, negociações, acordos políticos, o Presidente-General Ernesto Geisel assina em 11 de outubro de 1977 a lei complementar n. ${ }^{\circ} 31$ que cria o Estado de Mato Grosso do Sul, pelo desmembramento da área de Mato Grosso com capital em Campo Grande. Mato Grosso deixa de ser um para repartir-se em dois blocos distintos: Mato grosso com a capital em Cuiabá e Mato Grosso do Sul com sede administrativa em Campo Grande, cada qual com suas características próprias.

Carlos Magno ressalta o período da ditadura militar e diz que a divisão é fruto da mesma, onde a decisão de dividir Mato Grosso foi do Presidente-General Ernesto Geisel não havendo movimento popular, insurreição, reivindicação de alguma organização partidária ou cultural ${ }^{12}$.

De acordo com Ricardo de Souza da Silva:

Esta obra do pensamento autoritário que controlou o Estado brasileiro do golpe civil-mlitar de 1964 até meados da década de 1980, deixou os segmentos dominantes da sociedade local eufóricos na mesma medida que atônicos, pois, mesmo que o fato constituísse uma antiga aspiração e grande parte do "coronelismo" alocado na porção sul de Mato Grosso, há tempos a questão estava entregue ao esquecimento, era esporadicamente citada na imprensa ou no Parlamento Federal, sem maiores conseqüências ${ }^{13}$.

Maria Bittar enfatiza que Mato Grosso do Sul nasceu depois de uma longa jornada separatista protagonizada pelos proprietários rurais do sul do Estado. A sede do poder do norte, gerava incorformismo nos gupos latifundiários sulistas que se queixavam: "sabe-se que existe Mato Grosso pelo Talão do imposto". ${ }^{14}$

$\mathrm{O}$ isolamento do sul fez com que se tornasse um estado distinto enquanto estreitavam seus laços econômicos com São Paulo e mantinha afinidades com o

\footnotetext{
${ }^{12}$ AMARILHA, Carlos Magno Mieres. O Instituto Histórico e Geográfico de Mato Grosso do Sul e a construção de uma identidade sul-mato-grossense. Campo Grande: Ed: UCDB; p. 01.

${ }^{13}$ SILVA, Ricardo Souza. Mato Grosso do Sul: povoamento, memória e história. CPDO-UFMS.

${ }^{14}$ BITTAR, Marisa. Op.cit, p. 2.
} 
Paraguai, distanciando-se de sua própria capital. Assim, os grandes proprietários rurais sul-mato-grossenses, empenharam-se em uma trajetória cujo destino seria a criação de um estado para ser governado por si. De acordo com Paulo Roberto Cimó Queiroz os líderes sulistas buscam a máxima desvinculação possível em relação ao "Norte" - rejeitando, portanto, aquela idéia de Cuiabá como "cidade mãe" dos mato-grossenses. Assim, procura-se negar qualquer influência "cuiabana" no desenvolvimento da "civilização sulista". ${ }^{15}$

As imagens inculcadas pelos intelectuais nortistas e as ações políticas do governo estadual não eram bem recebidas, por parte de uma elite em ascensão no Sul de Mato Grosso, principalmente por moradores da cidade de Campo Grande.

Campo Grande já se transformara na segunda cidade do estado, o centro econômico e político do sul de Mato Grosso. Seus laços com São Paulo estreitavam-se cada vez mais intensamente, quer pela abertura da Estrada de Ferro Noroeste do Brasil, quer pela ressonância dos movimentos político-militares a partir da década de 20 . Sua vinculação a Cuiabá passa a ser mais administrativa enquanto as lideranças políticas do sul, a partir da experiência de 1932, começam a se projetar e a se organizar em termos da defesa dos interesses econômicos e políticos dessa porção do estado. ${ }^{16}$

A categoria dominante sul-mato-grossense contou com a elaboração de idéias sobre a necessidade de um novo estado, fazendo com que seu projeto fosse incorporado por toda a sociedade, tornando-se hegemônico. Ela gerou seus próprios intelectuais e esses intelectuais atuaram na obtenção do conhecimento, tanto de forma individual quando coletiva, destacando-se a Liga Sul Mato-Grossense (LSM), fundada em 1932 com o objetivo de pleitear a divisão do estado de Mato Grosso em dois Estados Federados e promover a união dos mato-grossenses.

Podemos concluir que, no sul de Mato Grosso, formou-se uma categoria de proprietários rurais, economicamente dominante que, com o tempo, sobrepôs a do norte. Não se sentindo culturalmente pertencente ao norte e não reconhecendo o governo estadual como seu, iniciou a resistência a ele.

A cisão cumpriria dois objetivos: a) proporcionar à classe dominante do sul de Mato Grosso um poder político que ela ainda não dispunha; b) criar um aparelho

\footnotetext{
${ }^{15}$ QUEIROZ, Paulo Roberto Cimó. Divisionismo e "identidade" mato-grossense e sul-matogrossense: um breve ensaio. CPDO-UFMS: Maio de 2005, p. 10.

${ }^{16}$ BITTAR, Marisa. Op.cit, p. 137.
} 
de Estado na porção territorial pela qual aquela classe nutria sentimento e pertença. O sentimento de não pertencer "a Cuiabá" aliou-se à força econômica, e depois política, dos fazendeiros do sul de Mato Grosso, que almejavam criar Mato Grosso do Sul.

Mato Grosso do Sul possui uma cultura multifacetada, resultado de um processo de interações e oposições ao longo do tempo. A proximidade geográfica com o Paraguai e a Bolívia, países com os quais faz fronteira geraram características sócio-culturais que o distingue dos demais estados brasileiros.

A divisão marca a pesquisa em torno da identidade. Dessa forma, a partir de 1978, um verdadeiro "surto" memorialístico desencadeou a publicação de inúmeras obras, constituindo-se em pouco tempo uma numerosa historiografia que passou a ser utilizada, pela falta de outras referências.

Sustento que, após a divisão do Estado (1977), Mato Grosso do sul, que nascia no contexto militar, ficava "órfão" de história, tendo em vista que toda a documentação foi transferida para a capital de Mato Grosso, Cuiabá. Nesse sentido, tornava-se eminente a construção de uma história do jovem estado, sobretudo uma história que estivesse de acordo com os desígnios de uma elite dominante que despontava no cenário regional e estadual ${ }^{17}$.

Seu surgimento está relacionado, num primeiro momento, com a necessidade de servir de suporte a uma identidade almejada, preocupada em registrar e descrever acontecimentos, lugares e personagens considerados importantes, num segundo ela se transforma em suporte de determinado poder. Nesse contexto é fundado o Instituto Histórico e Geográfico de Mato Grosso do Sul (IHG-MS) que se esmerou em formular e definir arquétipos identitários homogêneos em nome de todos os sul-mato-grossenses ${ }^{18}$. Elaborada por membros pertencentes às camadas dominantes, mas também por indivíduos com elas identificadas, essa historiografia aborda diversas temáticas, como o bandeirantismo, a Guerra do Paraguai e o Divisionismo.

${ }^{17}$ SQUINELO, Ana Paula. Construções e Representações do episodio da retirada da laguna na obra de Alfredo d'Escragnolle de Taunay. Anais do VI Encontro de História de Mato Grosso do Sul, 2002 , p.43.

${ }^{18}$ AMARILHA, Carlos Magno Mieres. O Instituto Histórico e Geográfico de Mato Grosso do Sul e a construção de uma identidade sul-mato-grossense. Campo Grande: Ed: UCDB; p. 2. 


\section{o movimento guaicuru como construção identitária}

Com a divisão territorial e política de Mato Grosso e o início da estruturação de Mato Grosso do Sul, os setores produtivos de arte e cultura se depararam com a necessidade de identificar os valores culturais da região correspondente ao novo Estado. Esse questionamento é muito intenso e exigiu uma profunda participação de pessoas relacionadas à questão, interessadas em conteúdo cultural para uma expressão estética.

Um desdobramento dessa prática foi a criação de um movimento cultural em 1979 em Campo Grande, denominado Unidade Guaicuru de Cultura, surgindo da ânsia de produtores regionalistas, que logo após a criação do Estado de Mato Grosso do Sul, encontravam-se em crise de identidade cultural posta pelo advento o novo estado. O objetivo, que já vinha sendo construído com base na História dos índios Guaicurus, era o de promover o gentílico “Guaicuru” em substituição ao já criado Estado de Mato Grosso do Sul.

Conclui-se que para identificar tal identidade seria necessária a compreensão de seu processo histórico-cultural. O movimento então optou na época por desenvolver um trabalho de retrospectiva histórica, identificando e resgatando as várias etapas do processo histórico, as referências, as características e os valores culturais do homem sul-mato-grossense e sua "evolução". Foi identificado o período Guaicuru como referência temporal desse processo, pois foi a nação Guaicuru a primeira plataforma social, econômica, política e cultural em abrangência territorial correspondente ao novo Estado. Neste contexto o termo "Guaicuru" até então pouco conhecido passou a ter importância existencial e significar a síntese referencial da identidade cultural de Mato Grosso do Sul, pois:

"guaicuru" é ao mesmo tempo essência e símbolo histórico cultural do povo deste Estado; e a configuração épica do homem nativo, consciente, guerreiro, lutador, resistente, autônomo, independente, que, por muito tempo a partir do pantanal, dominou de forma absoluta, sob égide de "cavaleiro guaicuru", o atual território do Estado de Mato Grosso do Sul. ${ }^{19}$

\footnotetext{
${ }^{19}$ SPENGLER, Henrique de Melo. Guaicuru. Mais Saber. Revista de Educação de Mato Grosso do Sul, n 3, 1999; p. 06.
} 
O Movimento Cultural Guaicuru tinha com meta a difusão do processo histórico e da identidade cultural do povo sul-mato-grossense e a divulgação dos valores e referências culturais da região em questão. Seu trabalho recebeu adesão de pessoas que nele encontravam identificação e afinidade. Com vista à descentralização, foi expandido o movimento criando sucursais em Dourados e em Coxim, sendo que em Coxim foi desenvolvido um projeto ecológico. Em Mato Grosso Sul são muitos os movimentos que nasceram e se desfizeram rapidamente, mas o movimento Guaicuru ganhou força sob a forma de Fundação Guaicuru de Cultura e Meio Ambiente:

Conscientes de que a cultura é o passaporte para o reconhecimento da própria identidade, algumas mentes idealistas mergulharam fundo na História, transpuseram as fronteiras da incompreensão, venceram preconceitos, até superar com a força das idéias, da palavra e das ações, antigos medos e inércias ${ }^{20}$.

A construção de determinada memória é uma das grandes metas do movimento, pois para seus integrantes o passado era o ponto de partida para a construção do presente e do futuro, porque só através da memória seria possível fazer o inventário da cultura e chegar à obtenção de uma determinada identidade.

Por anos consecutivos os artistas visuais do Movimento Cultural Guaicuru promoveram mostras de artes plásticas, com caráter itinerante e que aconteceram alternadamente na capital e nos pólos culturais do interior do Estado como Dourados, Corumbá, Aquidauana e Coxim. As primeiras "Mostras Guaicuru de Artes Plásticas" tinham caráter nativista e objetivavam divulgar obras e artistas engajados iconologicamente nesta corrente. Em seqüência, quando a relação sulmato-grossense-guaicuru tornou-se mais compreensível, as "Mostras" tornaramse regionalistas, divulgando a diversificada produção artística regional de Mato Grosso do Sul. Após vários anos de mostras de arte e de pesquisa organizam o Primeiro Fórum Guaicuru de Cultura com participação de diversos segmentos sociais, que forneceu elementos para a elaboração de um Plano Estadual de Cultura. O fórum foi realizado em 1990 na Universidade Federal de Mato Grosso do

${ }^{20}$ ROSA, Maria da Gloria Sá. Panfleto da IX mostra de artes plásticas. Caixa Fundação e Uso do Termo Guaicuru. Centro de Documentação Histórica da Região Norte de Mato Grosso do Sul/ Memorial Henrique de Melo Spengler (CDHRM). 
Sul e na oportunidade produziu-se um documento servindo de subsídio aos planos de Cultura do Estado ${ }^{21}$.

A temática Guaicuru tem sido constantemente revisitada. Em 1997 é lançado o filme "Brava gente Brasileira" uma co-produção que reúne três importantes nomes do cinema nacional: a diretora Lúcia Murat, o produtor Bruno Stroppiana e Buza Ferraz, ator, diretor e produtor. O filme tem direção e roteiro de Lúcia Murat, e retrata um episódio ocorrido em 1778, envolvendo índios Guaicurus e soldados do Forte Coimbra.

Em 1988 o $4^{\circ}$ Batalhão de Cavalaria Mecanizada de Dourados passou a se denominar Brigada Guaicurus, e criou em 1997 um boletim informativo com o nome de $\mathrm{O}$ Guaicuru que o define como índio cavaleiro que dominou a região norte do Rio Apa. O editorial de O Guaicuru, ano 2, n.7, de julho de 1998, tem como título A tradição Guaicurus:

Os registros da história justificam plenamente o orgulho que a $4^{\circ}$ Brigada de Cavalaria Mecanizada sente em levar no seu estandarte o nome de primitivos guerreiros "brasileiros".

${ }^{21}$ Diversos outros eventos foram realizados pelos membros do Movimento Guaicuru dentre eles podemos citar: O Centro Social de Cultura Nativa de MS, o grupo Acaba, o grupo Garra e o Referencial Guaicuru de Artes Plásticas, através da Unidade Guaicuru de Cultura, promoveram de 19 a 21 de agosto de 1991 o Ciclo de Palestras e Debates em comemoração aos 200 anos do Tratado de Paz e Aliança Eterna, assinado em 17 de agosto de 1791 entre a Nação Guaicuru e a Coroa Portuguesa, pelo qual o povo Guaicuru reconheceu a soberania de Portugal e o território sul-mato-grossense foi definitivamente incorporado ao Brasil. O Ciclo de Palestras e Debates teve como tema o Tratado de Paz e Aliança Eterna, o Projeto. Taquari de conservação ecológica do rio Taquari, desenvolvido pela Unidade Guaicuru de Cultura e por fim uma sessão solene em comemoração ao bicentenário do Tratado Guaicuru de Paz e Aliança Eterna.

No ano de 1993 dos dias 07 à 09 de maio foi realizado pela Secretaria Municipal de Cultura e do Esporte em parceria com a Unidade Guaicuru de Cultura o $1^{\circ}$ Fórum Municipal de Cultura de Campo Grande - Arte e Cultura em Debate. Houve seis mesas de debates com os seguintes temas: "Projetos, programas e políticas culturais", "Leis de incentivos fiscais a cultura", "Arte, cultura e cidadania", "Artes e ciências na memória cultural", "Utilização cultural dos espaços públicos" e "Projeto cultura". Estas mesas tinham o objetivo de buscar na sociedade civil estratégias participativas na condução da produção de arte do município.

Em 1996 o movimento encabeçou uma ação conjunta que, através de um trabalho de sensibilização da comunidade, colheu em abaixo-assinado a solicitação ao prefeito municipal de Coxim a aquisição do terreno e do imóvel onde morava Zacarias Mourão. No terreno encontra-se a casa e o quintal onde, durante parte da infância e adolescência, residiu Zacarias Mourão, encontra-se o Pé de Cedro símbolo da cultura Coxinense. O terreno foi adquirido com anuência da Câmara Municipal e transformado na praça Zacarias Mourão. Cf: Documentos Diversos. Centro de Documentação Histórica da Região Norte de Mato Grosso do Sul/Memorial Henrique de Melo Spengler (CDHRM). 
Os Guaicurus participaram ativamente das campanhas do Brasil - Colônia e do Brasil Império, para a conquista e manutenção do território, ajudando os portugueses a defender o país dos castelhanos. [...] O autóctone espírito de manter a integridade territorial e a letalidade das cargas de cavalaria guaicurus são vetores que atravessam a história e alinham-se harmonicamente (grifo do autor) com a missão e com grande mobilidade e potência de fogo da $4^{\circ}$ Brigada de Cavalaria Mecanizada. ${ }^{22}$ [Grifos nossos]

Em 2000 houve um movimento para mudar o nome do Estado de Mato Grosso do Sul para Estado do Pantanal. No mês de janeiro esse movimento funda a Liga Pró-Estado do Pantanal e cria um jornal para a difusão de suas lutas, onde mais uma vez o nome do jornal é O Guaicuru. E no primeiro semestre de 2002 a Universidade Estácio de Sá, em Campo Grande, cria o seu campus e o batiza de Guaicuru.

Guaicuru é para o povo sul-mato-grossense, um termo forte, histórico, superior, lembrando os índios cavaleiros, orgulhosos e destemidos, que dominavam as vastas campinas e planalto da província, do oeste ao rio Paraná, e que, a partir do final do século 18, formava a extensa vacaria do gentio Guaicuru. Lenta e irreversivelmente, cresce esta outra tribo, também Guaicuru, interessada somente.

no resgate e no desenvolvimento das artes sul-mato-grossenses, num trabalho árduo, desinteressado, nem sempre reconhecido. Como o patrono, é forte, altaneira, e cumpre seu destino, perpetuando-lhe o nome, que não pode desaparecer da nossa história. Ao contrário. Aos poucos, Guaicuru (negrito do autor) vai fixando-se como sinônimo de sul-mato-grossense, como epônimo de Mato Grosso do Sul, empregado, com orgulho, por todos os que, neste Estado, trabalham e constroem a história, a cultura e o progresso deste rincão. ${ }^{23}$

Assim, à guisa de conclusão reiteramos que o Estado de Mato Grosso do Sul "nasceu" depois de uma longa jornada separatista protagonizada pelos proprietários rurais no sul de Mato Grosso, onde se formou uma categoria de proprietários rurais, economicamente dominantes, que, com o tempo sobrepôs a do norte iniciando resistência a ele. Pode-se perceber que após a divisão territorial e política de Mato Grosso e o início da estruturação de Mato Grosso do Sul, houve um questionamento acerca da

${ }^{22}$ O Guaicuru-jornal da $4^{\circ}$ Brigada de Cavalaria Mecanizada, Dourados, ano 2, n. 7, jul. 1998. APUD: ZILIANE, José Carlos. Tentativa de definir a identidade em Mato Grosso do Sul pelo gentílico Guaicuru. Anais do VI Encontro de História de Mato Grosso do Sul. "Mato Grosso do Sul: Memória e Identidades". Campo Grande: UCDB, 2002, p. 177.

${ }^{23}$ CAMESTRINI, Hidelbrando. Panfleto da XII Mostra Guaicuru de Artes Plásticas. Caixa Fundação e Uso do Termo Guaicuru. Centro de Documentação Histórica da Região Norte de Mato Grosso do Sul/Memorial Henrique de Mel Spengler (CDHRM). 
identidade do novo Estado. A partir desse questionamento há uma tentativa de construção de uma determinada identidade no estado que se deu fundamentalmente por artistas e intelectuais a partir do Movimento Guaicuru que buscaram uma reposta a crise identitária do período em questão. Diante disso, o Movimento Guaicuru optou em desenvolver um trabalho de retrospectiva histórica, identificando e resgatando as várias etapas do processo histórico, as referências, as características e os valores culturais do homem sul-mato-grossense e sua "evolução", identificado o período Guaicuru como referência temporal desse processo, fazendo com que a temática Guaicuru fosse constantemente revisitada seja por artistas vinculados ao movimento seja por interpretações posteriores que incorporaram e legitimaram o gentílico guaicuru.

É curioso verificar como essa "idéia-força”" chamada nação guaicuru congregou pessoas transformando aos poucos a noção de acontecimento para fato histórico. O movimento guaicuru retoma o passado - no caso a nação guaicuru - a fim de construir uma nova concepção de presente e de futuro, essa noção de história parte da premissa da luta pelo futuro a partir de uma memória de um passado ${ }^{24}$. O conhecimento histórico, portanto, se distingue por meio da interpretação historiográfica que se tornou fato, pela memória histórica ${ }^{25}$, e não necessariamente pela experiência do movimento. O sentido histórico alcançado é expresso pelos momentos escolhidos no passado, a partir de um ideal de "guerreiro, forte e lutador" que consolida uma interpretação de passado, um projeto de presente e fundamentalmente de futuro. Além disso, o próprio sentido de identidade perde sua dimensão de luta e embate e torna-se hegemônico, na medida em que há um projeto de construção de uma identidade cultural que se torna vencedora e legitimadora de ícones e propostas imagéticas. Enfim, a imagem da nação Guaicuru como elemento para construção identitária de Mato Grosso do Sul pós-movimento divisionista foi utilizada como representativa de um povo guerreiro, lutador, resistente, símbolo de grande determinação sendo assim, o Mato Grosso do Sul teria suporte no passado para projetar a partir desses ícones uma diferença em relação ao Mato Grosso.

\footnotetext{
${ }^{24}$ Essa noção de história pode ser discutida a partir dos conceitos de história de Walter Benjamin. Cf.: BENJAMIN, Walter. Sobre o conceito de história. In: BENAJMIN, Walter. Magia, técnica, Arte e política: ensaios sobre literatura e história da cultura. São Paulo: Brasiliense, 1994. - (Obras escolhidas; v. 1)

${ }^{25} \mathrm{O}$ conceito de memória história aqui se refere ao citado por Carlos Alberto Vesentini. Cf.: VESENTINI, Carlos Alberto. A teia do fato. São Paulo: Hucitec/História Social-USP, 1997.
} 